\title{
HISTÓRICO SOBRE A IMPLANTAÇÃO DO PACS E PSF NO ESTADO DO PARÁ
}

Cecilia Helena L. da Costa ${ }^{1}$

No Estado do Pará, o Programa de Agentes Comunitários de Saúde foi implantado no ano de 1991, em 23 municípios, com 1.174.

Entretanto, em 1992, com o surgimento da cólera no Estado, houve a necessidade de priorizar a implantação do PACS nas áreas de maior incidência como medida de controle. Contornado a situação da Cólera no Estado, voltou-se a atender a solicitação do Ministério da Saúde para implantação do programa nos demais municípios que manifestaram interesse.

Atualmente o Estado conta 7.992 ACS, distribuídos em 137 municípios e tendo como meta a Implantação e expansão de 11.992 Agentes Comunitários, totalizando um percentual de cobertura de $85 \%$ da necessidade do Estado. No ano de 1994, ocorreu a implantação do Programa de Saúde da Família no Estado, nos municípios de Bragança e Redenção. Em Bragança, município situado na mesoregião Nordeste, houve a formação inicial de 02 equipes, e em Redenção, situado na mesoregião sudeste, o programa começou com a formação de 03 equipes.

Essas equipes desenvolviam atividades de promoção, proteção e recuperação da saúde da população, entretanto, face a necessidade de orientação e acompanhamento apresentavam dificuldades em corresponder à filosofia do programa.

Até este momento, estão em atividade 128 equipes, distribuídas em 51 municípios, o que representa $39,8 \%$ do total do Estado.

Durante a implantação das Estratégias do PACS e PSF no Estado, as pessoas envolvidas neste processo, tiveram que enfrentar algumas dificuldades, tais como:

- Morosidade no repasse dos recursos financeiros que eram liberados pelo nível Central da Secretaria Executiva de Saúde Pública, para o pagamento das A.C.S. nos municípios;

- Perfil da escolaridade dos A.C.S., pois apenas 33\% tinham o $1^{\circ}$ grau completo, enquanto que $67 \%$ apresentavam o $1^{\circ}$ grau incompleto;

- Dificuldade de acesso por parte dos AC.S. e Instrutor/Supervisor para a realização de suas atividades ocasionada pela distância, acidentes geográficos e falta de transporte para deslocamentos dos mesmos;

- A desativação do PACS em algum municípios, por falta do Instrutor / Supervisor;

- Falta de organização do processo seletivo para os A. C.S, não havendo maior divulgação nas comunidades, e consequentemente não havendo candidatos para as comunidades programadas, quanto à inscrição e participação no processo de seleção;

- Atraso dos vencimentos dos A. C.S. e Instrutor / Supervisor que atuavam no programa;

- Dificuldade na contratação do profissional enfermeiro em municípios longínquos e de difícil acesso;

- Falta de organização do município quanto ao processo de municipalização;

- Grande rotatividade dos Instrutores / Supervisores e médicos das Estratégias do PACS e PSF.

Mas, apesar dos entraves encontrados no decorrer do processo, conseguimos superar alguns e como recompensa, obtivemos os seguintes resultados:

\footnotetext{
${ }^{1}$ Coordenadora Estadual do PACS/PSF do Estado do Pará.
} 
- O controle e diminuição de casos de cólera no Estado;

- Maior cobertura do PACS no estado do Pará (56\% da população) e maior representatividade do PSF no Estado (39.8\% da população);

- Repasse dos recursos do SUS, diretamente do Fundo Nacional de Saúde para os fundos municípios de saúde, ficando o gestor municipal com total liberdade de usar os recursos para assegurar atendimento à sua população;

- A Contribuição das Estratégias do PACS no processo de municipalização. Dos 143 municípios paraenses, 132 estão municipalizados;

- Busca ativa dos casos de TB/MH e SM;

- Melhoria do controle das endemias;

- Aumento da cobertura vacinal;

- Maior investimento dos gestores municipais nas Estratégias do PACS/PSF;

- Vencimentos atualizados e compatível com a categoria profissional do médico, entretanto o do profissional enfermeiro ainda necessita ser melhorado.

A seguir, mostraremos algumas experiências sobre o PSF nos municípios de Bragança e Barcarena.

Em se tratando de experiências sobre a estratégia Saúde da Família, na qual o profissional enfermeiro, juntamente com os demais componentes da equipe estão envolvidos, no sentido de proporcionar melhor qualidade de vida à nossa população, citaremos, neste primeiro momento, algumas experiências dos municípios pertencentes ao Estado do Pará, que poderão servir como contribuição para outros Estados.

Iniciaremos pelo município de Bragança, onde podemos destacar as campanhas educativas sobre: Hanseníase, Prevenção do Câncer de Mama e Uterino, Hipertensão Arterial, Aleitamento Materno e Mutirão do Lixo.

A Campanha sobre Hanseníase aconteceu no mês de Abril/98, na Comunidade de Vila Sinhá, onde foram envolvidos além da E. S. F., outros profissionais de nível superior que não integram a equipe tais como: Enfermeiras (04); Técnico de Laboratório (03); Farmacêutico-Bioquímico (01); Assistente Social (01); além da participação maciça da comunidade.

Durante a Campanha, encontramos algumas dificuldades sobre a falta de informação da comunidade assistida sobre a doença e o planejamento tardio do evento para a divulgação nos bairros, pois a equipe não enviou o cronograma de treinamento.

Quanto aos resultados esperados, pudemos observar que houve uma melhor sensibilização e conscientização da população sobre a doença, havendo o controle eficaz dos faltosos e aumento da divulgação na comunidade e responsabilidade no diagnóstico e tratamento de casos novos.

A Campanha sobre o Câncer de Mama e Uterino, realizada em dezembro de 1999, na comunidade de Vila Sinhá envolveu todas as equipes de Saúde da Família.

No desenrolar dos trabalhos, os mesmos enfrentaram algumas dificuldades quanto a questões culturais e tabus, mas com esforço e dedicação, conseguiram superar os entraves e assim atingir os objetivos propostos que era a realização de cinqüenta (50) preventivos e a participação ativa das mulheres da comunidade, quanto ao conhecimento e realização do auto-exame de mama.

Ainda, na comunidade de Vila Sinhá, em agosto de 1999, foi realizada uma campanha sobre Aleitamento Materno, não encontrando nenhuma dificuldade quanto à realização da mesma, e tendo como resultado esperado a participação e conscientização das mães à cerca do Aleitamento Materno Exclusivo, estando à frente as enfermeiras que integram as três equipes do P.S.F.

Quanto à Campanha de Mutirão do Lixo, a mesma aconteceu no mês de fevereiro/99, na mesma comunidade, onde foram envolvidos além da equipe, quatro (04) lideres comunitários e seis (06) garis de Prefeitura de Bragança.

Em se tratando de dificuldades encontradas, os mesmos tiveram que enfrentar o período chuvoso que atrapalhou parcialmente a Campanha e a falha no carro coletor para os dias marcados.

Como êxito, durante e após a Campanha, os profissionais envolvidos obtiveram adesão quase total das população para maior conscientização da população no que diz respeito ao acondicionamento do lixo. 
Com relação ao município de Barcarena, enfatizaremos a experiência vivida pela equipe do P.S.F. de Castanhalzinho que desenvolve um trabalho com plantas medicinais da região, onde foram catalogados vários tratamentos alternativos com a participação do médico da equipe que tem uma formação em Homeopatia.

Entretanto ainda é um trabalho árduo, pois a comunidade está acostumada com "medicalização" das últimas décadas, inclusive está sendo desenvolvido um estudo comparativo nos tratamentos alopáticos e alternativos com as referidas plantas medicinais, cujo resultado será futuramente divulgado.

Outras experiências foram realizadas no campo social, para angariar fundos em prol da comunidade para aquisição de cestas básicas e brinquedos para serem distribuídos durante o natal, entre as famílias carentes, tendo o apoio da própria comunidade e da empresa Albrás.

Outro evento realizado foi o Campeonato de Futebol Amador Rural, que mobilizou as comunidades assistidas, com o objetivo de angariar recursos que seriam investidos em uma horta comunitária.

Diante do que foi exposto, esperamos contribuir para o engrandecimento da Estratégia de Saúde da Família e assim somar esforços para que este novo modelo seja eficiente e possa garantir melhoria na qualidade de vida a toda nação brasileira. 